\title{
Un-hiding maps @brooklynhistory: Strategies for outreach in times of austerity
}

Carolyn Hansen, Project Map Cataloger, Brooklyn Historical Society chansen@brooklynhistory.org

Brooklyn Historical Society

128 Pierrepont St.

Brooklyn, NY 11201

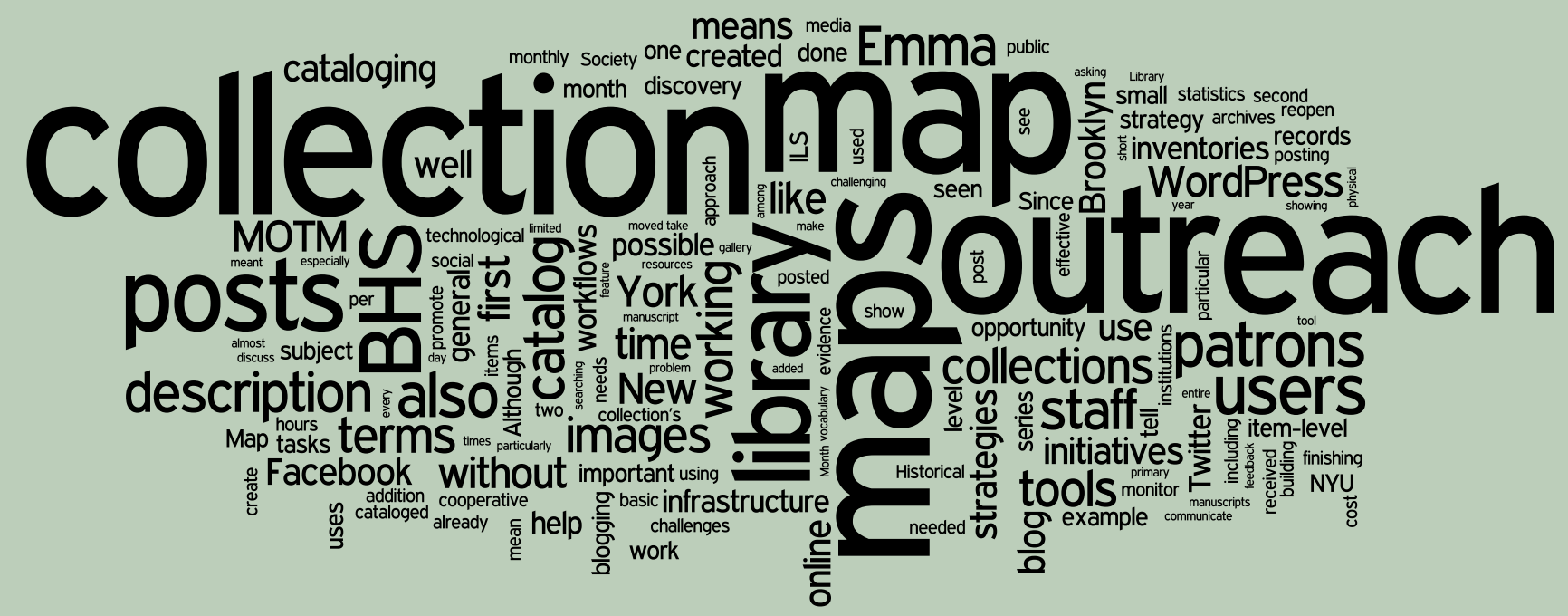

ABSTRACT

This article describes map outreach initiatives at the Brooklyn Historical Society (BHS), a non-profit museum, library and archives, and education center located in Brooklyn, New York. In particular, it explores how BHS staff prioritized outreach under budget constraints, created successful workflows, and employed tools to help patrons discover the map collection.

KEYWORDS: maps, outreach, workflows, social media, WordPress

\section{INTRODUCTION}

Although "un-hiding" is not technically a word, I use it deliberately when describing map outreach at the Brooklyn Historical Society (BHS, www. brooklynhistory.org). This is because when I started work as BHS' Project Map Cataloger in February 2010, very few people outside of our library seemed to be aware of the collection's existence. While similar institutions in our community (such as the New York Public Library or the New York Historical Society) had online catalogs filled with map records or digital galleries representing their 
cartographic resources, BHS' maps had almost no online presence. The maps had not been cataloged, nor was there a collection description or inventory online.

Our maps were, quite literally, hidden from the public by a lack of discovery tools. We needed to promote the collection, but the promotion would have to fall within certain parameters. In short, it would need to be fast and inexpensive.

This article will describe the map outreach campaign at BHS; in particular, how our library prioritized outreach under budget constraints, created successful workflows, and employed tools to help patrons discover the map collection. Although this is an ongoing process, we have already seen an increased public awareness of our map collection as a result of these initiatives; for example, patrons are visiting the library and requesting to see the maps, and hundreds of people view maps on our blog each month. While our discovery tools are not perfect-and incorporating outreach into already full calendars has been challenging - the public response has been extremely encouraging.

Before discussing our outreach methods, it is important to describe the history of the map collection at BHS and, in particular, why our maps were hidden in the first place. Living in 2011 presents certain technological expectations

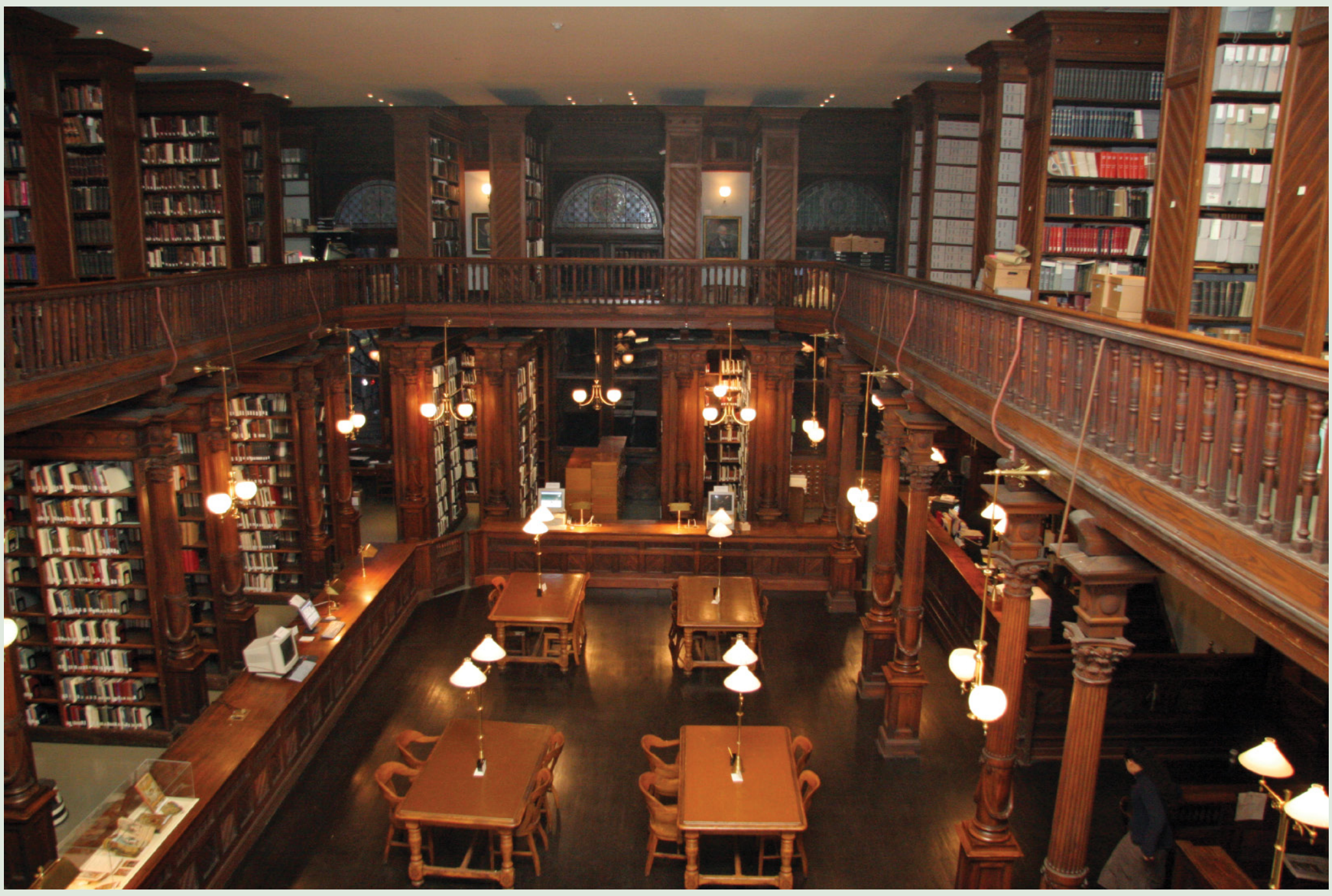

Figure 1. BHS' Othmer Library, circa 2008. Courtesy of the Brooklyn Historical Society. 
to librarians, and our library has felt this acutely. Patrons expect the map collection to be cataloged and fully digitized, but we are still working to catalog the collection and do not have the infrastructure to digitize the maps. The reasons why we are behind technologically are linked to our institutional history.

BHS was founded in 1863 and the organization moved into its current building in Brooklyn Heights, New York, in 1881. In the late 1990s, the entire building was closed for renovations, which meant that all of the library collections were moved into off-site storage. The building did not reopen until almost a decade later, and collections were brought back gradually over time. This presented enormous challenges for the library, especially in terms of physical and intellectual control of the collections. Simply put, outreach could not be a priority when the library was understaffed and struggling to reopen after a decade of being closed. It is a testament to the hard work and dedication of our staff that the library did successfully reopen, gain control over its collections, and begin outreach initiatives. Then, in December 2009, the library received a significant grant from the Council on Learning and Information Resources (CLIR), to catalog its 19th century holdings (including the map collection) as well as archives and manuscripts. It was under the auspices of this grant that I was hired to begin cataloging the map collection.

\section{THE COLLECTION}

BHS' map collection consists of approximately 3,000 maps and atlases spanning the years circa 1570-2011. The main geographic scope of the collection is Brooklyn, New York City, and Long Island, although there are outliers due to previous collecting policies that were more geographically inclusive. The collection contains a wide variety of different types of maps, including, but not limited to: physical maps, political maps, transportation maps, property maps, survey maps, pictorial maps, manuscript maps, topographic maps, cultural maps, and nautical charts. Among the collection's highlights are rare items such as the first state of Bernard Ratzer's "Plan of the City of New York" and unique materials like 19th century manuscript maps of Brooklyn created by the Bergen and Pierrepont families. The following images showcase some of our most popular items.

\section{THE CHALLENGES OF OUTREACH}

Although the need for map outreach was not in dispute among our staff, there were significant challenges to actually working on it. ${ }^{1}$ These challenges were a result of our institution's limitations, specifically, a lack of funding, staff, and technological infrastructure. However, the primary challenge was (and continues to be) the opportunity cost for working on outreach. There are only

\footnotetext{
${ }^{1}$ I would like to stress that map outreach is part of a larger, institution-wide outreach campaign. BHS library staff is currently working to provide access to all of our resources, including special collections, archives and manuscripts, photographs, and oral histories.
} 


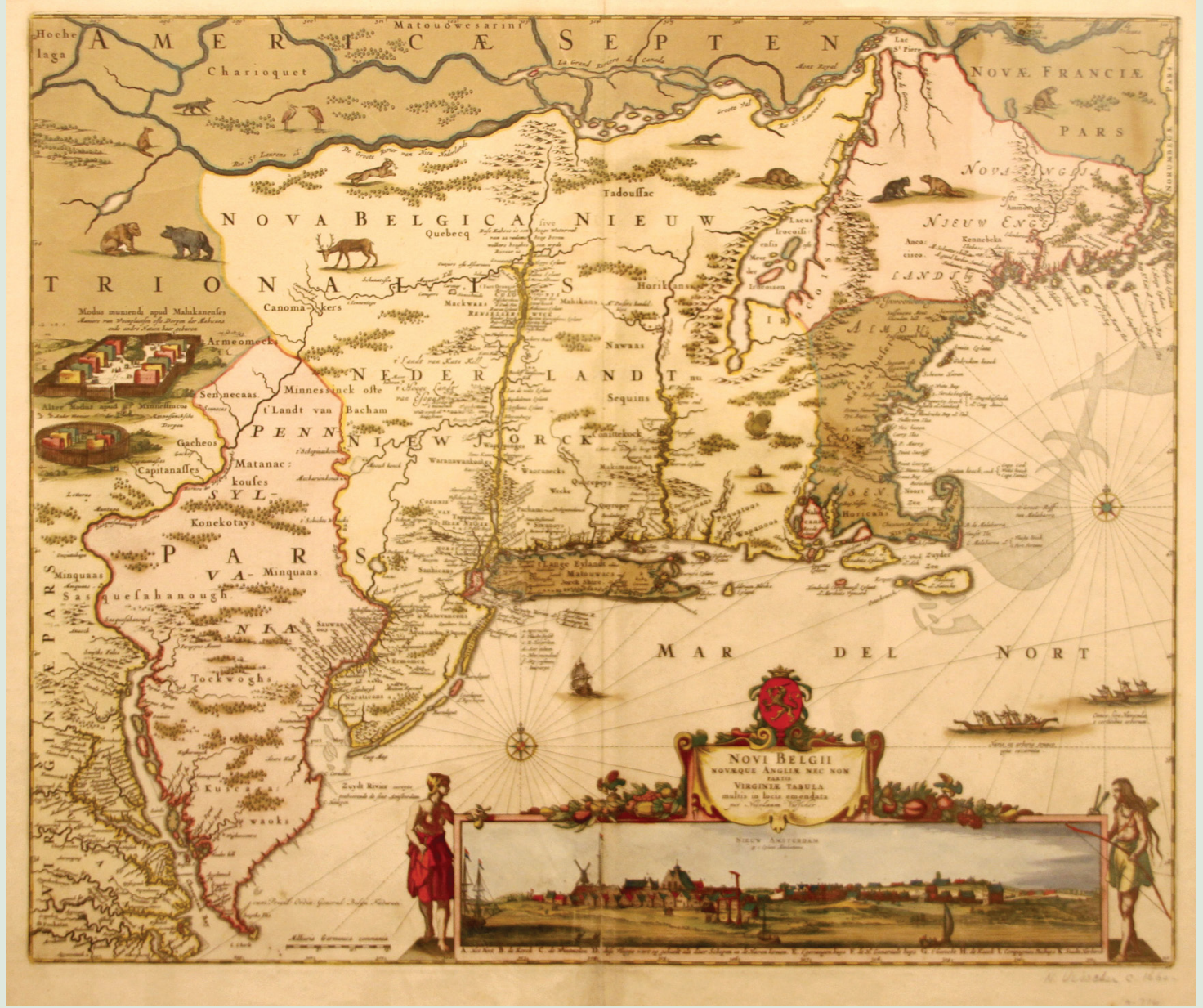

Figure 2. "Novi Belgii: Novaeque Angliae nec non partis Virginiae tabula multis in locis emendata." Nicolas Visscher. circa 1684. Brooklyn Historical Society Map Collection.

so many hours in a day and prioritizing one thing over another means that the other activity is not getting done. In other words, any time I spent on outreach was costing time cataloging or working on collection management. The question became "How can we incorporate outreach into existing workflows without jeopardizing other tasks?"

The answer to this question was to approach outreach in a smart and systematic fashion and to employ strategies that made it as time-efficient as possible. The first of these strategies is very basic, but it underlies all of my outreach activities: work small. By this, I mean concentrating on small, clearly defined tasks as opposed to big projects. The benefits of working on small activities are three-fold: first, they will actually get done; second, they help prevent staff burnout by giving us the satisfaction of completing tasks; and third, they limit the opportunity cost of working on outreach. A second, related strategy is pare it down. By this, I mean isolating a problem and stripping away all superfluous aspects until you are at the problem's core, and then designing solutions to solve the problem. By approaching outreach with these strategies in mind, I have successfully incorporated it into my schedule without feeling like it has subsumed other priorities. 
All of our outreach tools are designed to be user-friendly, simple, and effective. These include more modern tools like WordPress, Facebook, and Twitter, as well as traditional tools like MARC (machine-readable cataloging) catalog records. The first tool that I will discuss is WordPress (wordpress.org), the web software used to create blogs or websites. Our library uses WordPress for both our blog (brooklynhistory.org/blog) and our catablog Emma (brooklynhistory.org/library/wp).

In general, blogging can be an excellent means of communicating with users and displaying images of your collection, but it needs to be done efficiently. For me, this meant applying my general outreach strategies, particularly pare it down. I thought about my posting as a means to solve problems and asked myself: How can my posts help users learn about the collection? What needs aren't being met? Through conversations with staff and patrons, I came to two basic conclusions: users needed to know of the collection's existence and they needed to see images of it. Once these needs were identified, it was possible to design strategies to meet them. The first strategy was to blog monthly about some aspect of the collection and the second was a series called "Map

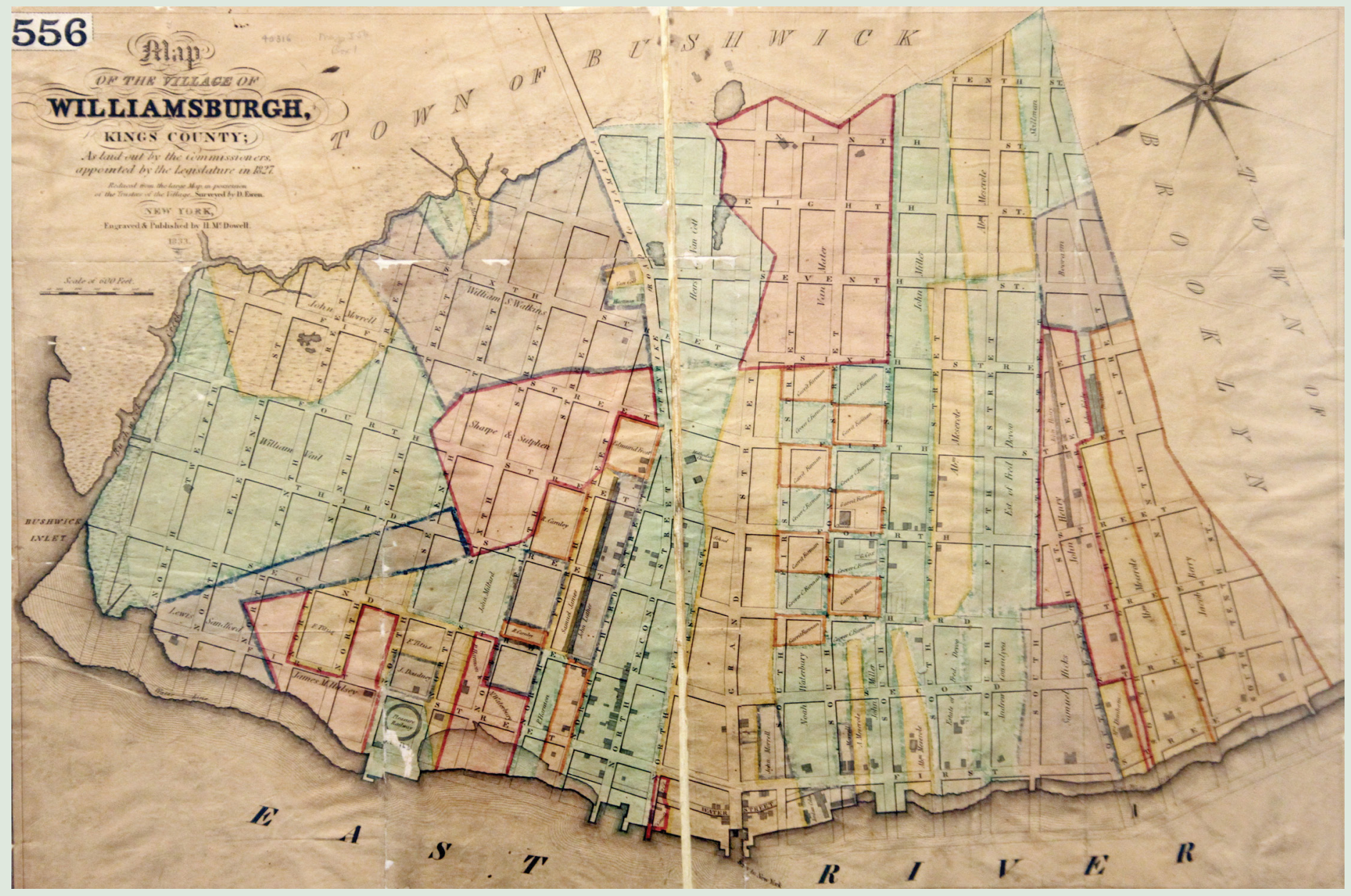

Figure 3. "Map of the village of Williamsburgh, Kings County: as laid out by the Commissioners appointed by the Legislature in 1827: reduced from the large map in possession of the Trustees of the Village." D. Ewen. 1833. Brooklyn Historical Society Map Collection. 
of the Month (MOTM)," which featured one map from our collection every month. Modeled after an existing BHS series called "Photo of the Week," MOTM was a very simple idea designed to increase images of the collection online. Since we did not have the infrastructure for a digital gallery with formal metadata, the blog could serve as our temporary gallery. In order to maximize efficiency, the posts would not be text-heavy, containing only a brief description of each map's contents. The workflow consisted of one session per year, in which I would photograph the maps, upload images, write posts, and save them as drafts in the WordPress queue. By working on all of the year's posts at one time, I had the satisfaction of finishing the task while preventing future procrastination.

\section{In addition to MOTM, I}

would also blog monthly about a feature of the collection. These posts showcase my general outreach strategies as well as my key blogging strategy: show, don't tell. What I mean by this is that posts should be heavy on map images and light on explanatory text. Since maps are so visually compelling, their images can be the focal point of the post in a way that something more cerebral, like a series of letters, cannot be. Map librarians should take advantage of this and trust that their maps are strong enough to tell a story without pages of footnotes or interpretive text. In terms of workflows, show, don't tell also has the added benefit of reducing the time it takes to create posts. For example, my monthly posts do not take more than two hours to complete, including time to photograph maps and upload images. The frequency of my posts would not be possible without the show, don't tell strategy.

In addition to blogging, our library uses WordPress for our catablog Emma, which provides collection-level description of the library's archives, manuscripts, and special collections. Emma was created in 2008 by library staff as a means of 
communicating to users about archival collections. It also provides a platform for the library to post finding aids and collection descriptions online without needing the infrastructure required of EAD (encoded archival description) or an ILS (integrated library system). Emma has the added benefit of being indexed by major search engines like Google so it is easy for users to find.

In terms of the map collection, we have posted a collection description on Emma, as well as inventories of the entire map collection. This is beneficial in several ways: first, because not all of the maps are currently cataloged, the inventories provide some level of access to our uncataloged maps. The inventories are not as rich in terms of description as an item-level catalog record but they provide at least a base line level of access. In the inventories, we include basic bibliographic information at the item level, such as title, date, call number, and subject. The subjects are taken from an internally created local vocabulary, which has also been posted to Emma so that patrons can search the inventories more effectively. I also use the Emma description as an opportunity to communicate about the subject headings that I use in item-level cataloging. This is very important because I can list the most commonly used subject terms from LCSH (Library of Congress Subject Headings) and then refer users to our online catalog BobCat, where item level-records are stored. Since controlled vocabularies like LCSH are notoriously counter-intuitive and users are often unaware of what words the cataloger is using, listing subject terms can help make users' searching more effective. Additionally, I use the Emma description as a means to educate users about map-specific vocabulary, particularly genre terms, which are becoming increasingly important in map cataloging.

In addition to WordPress, BHS uses Facebook and Twitter to communicate about collections. My approach to posting follows my general outreach principles as well as the common adage less is more. I am very conscious of the addictive quality of social media, especially the urge to post throughout the day or monitor responses. In short, the opportunity cost of using social media can become too high if it prevents me from finishing other tasks. It is also important to recognize that constant posting can cause information overload and, if my readers become overwhelmed by the frequency of my posts, they are likely to stop reading. While I want to share every exciting discovery about the collection, my posts are more effective if they are staggered. In general, our map-related posts on Facebook and Twitter are used to promote blogging or events. This totals approximately three posts to Facebook and Twitter per month, providing users with updates on the collection without overwhelming them.

The last outreach tool I will discuss is the most traditional: item-level cataloging. As described earlier, our library uses Emma for description at the collection level; however, I also create item-level records for the map collection. Since BHS does not currently have the technological infrastructure or staff to maintain its own ILS, we use BobCat, a cooperative catalog hosted by New York University (NYU). Our library has an annual contract with NYU, allowing us to rent space in the catalog. NYU also exports all of our records to OCLC, making our items available in the international catalog WorldCat. The cooperative catalog allows us the convenience and searching capabilities of an 
ILS without having to worry about technical issues. The NYU consortium could serve as a model for other institutions that do not have the ability to host an ILS. If there is a large institution in your area, consider asking if a cooperative is possible.

\section{OUTCOMES}

Although our map outreach initiatives have only been in place for about a year, we have already seen positive results. In terms of measurement, we monitor progress by statistics as well as anecdotal evidence and word of mouth. For statistics, we use Google Analytics to track visits to our blog and website. These statistics have shown that MOTM and map collection posts are very popular, consistently finishing in the top five most visited posts. We also monitor retweets and have found that map tweets are among our most highly retweeted. For example, a tweet about August 2011's MOTM showing a map of Williamsburgh received more than twice the retweets of any of BHS' tweets that summer.

Anecdotal evidence, while not scientific, is also showing that the outreach initiatives are working. MOTM and other map posts have received lots of positive feedback from patrons and members of the community. For example, @teachnypl tweeted “@nyplmaps may get jealous but we couldn't resist the @ brooklynhistory series Map of the Month. One can love many maps" and on Facebook, a patron named Elana posted "Drool. LOVE the map feature." This is just a small sampling of feedback we have seen on Facebook and Twitter. Additionally, I have had patrons approach me during open hours with printed out copies of the MOTM, asking to see the map in person. I work at the reference desk two to four times per month and I have definitely seen an increase in map requests from patrons, both on-site and remotely. One of the primary goals of map outreach was to make patrons aware that our collection existed, and anecdotal evidence suggests that this is occurring.

\section{CONCLUSION}

I hope that our success in map outreach at BHS will inspire other institutions to launch similar initiatives. Even in times of financial difficulty with limited numbers of staff, there is much that can be done to promote a collection. This means making difficult decisions in term of time management and requires a commitment to consistent outreach measures. While this is challenging, I believe it is absolutely imperative that our collections are visible and accessible to users. As libraries, we are only relevant if patrons are using our resources, and they cannot do so unless they are provided with discovery tools. "Un-hiding" doesn't happen overnight, but it is possible with creativity and perseverance. 